\title{
Solar Light-Driven Photocatalysis Using BaFe204/rGO for Chlorhexidine Digluconate Contaminated Water: Comparison With Artificial UV and Visible Light-Mediated Photocatalysis
}

\section{Astha Singh}

Indian Institute of Technology (Indian School of Mines): Indian Institute of Technology

Brijesh Kumar Mishra ( $\square$ bkmishra3@rediffmail.com )

Indian Institute of Technolgy (ISM) https://orcid.org/0000-0002-4451-1924

\section{Research Article}

Keywords: Chlorhexidine Digluconate, BaFe2O4/rGO, Adsorption combining Photocatalysis, Energy Efficiency

Posted Date: April 28th, 2021

DOl: https://doi.org/10.21203/rs.3.rs-386420/v1

License: (c) (1) This work is licensed under a Creative Commons Attribution 4.0 International License. Read Full License

Version of Record: A version of this preprint was published at Environmental Science and Pollution Research on January 7th, 2022. See the published version at https://doi.org/10.1007/s11356-021-176898. 


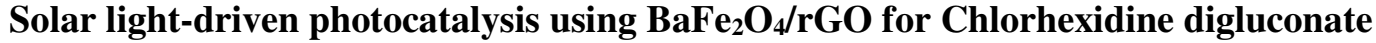 contaminated water: comparison with artificial UV and visible light-mediated photocatalysis.}

\author{
Astha Singh ${ }^{\mathrm{a}}$, and Brijesh Kumar Mishra ${ }^{\mathrm{a} *}$ \\ ${ }^{a}$ Department of Environmental Science and Engineering., Indian Institute of Technology (Indian \\ School of Mines), Dhanbad-826004, India \\ a* Corresponding Author: brijesh@iitism.ac.in \\ a singh.astha0689@gmail.com
}

\begin{abstract}
Synthesis and characterization of dual functioning material is an effective approach for promotion of organic pollutant degradation through adsorption as well as photocatalysis. Herein, graphene oxide modified by addition of barium nitrate and iron to construct smooth sheet-like structure $\left(\mathrm{BaFe}_{2} \mathrm{O}_{4} / \mathrm{rGO}\right)$ for removal of Chlorhexidine Digluconate (CHD). Compare with GO (75.69\% -UVlight ;88.17\%-visible-light), $\mathrm{BaFe}_{2} \mathrm{O}_{4} / \mathrm{rGO}$ showed significant adsorption-photocatalysis effect under visible-light $(93.95 \%)$ than UV-light (78.17\%). The introduction of barium nitrate and iron into graphene oxide led to smooth porous structure with increased surface area $\left(93.66 \mathrm{~m}^{2} \mathrm{~g}^{-1}\right)$, which resulted in large number of adsorption active site and great photocatalytic activity with efficient charge separation. Although, catalysts did not mineralize CHD completely, but the parent compound mineralized to some extent, which was confirmed by the TOC measurement and $\mathrm{UV}_{254}$ absorbance variation. In addition, toxicity of degraded products was analyzed by bacterial susceptibility test on Bacillus cereus DPAML065 suggested that nontoxic byproducts of CHD formed, which led to their safe disposal. Based on the identified transformed products, the possible degradation pathway was proposed. Batch studies demonstrated that $\mathrm{BaFe}_{2} \mathrm{O}_{4} / \mathrm{rGO}$ is highly photoactive based on reaction rate constant $\left(\mathrm{R}^{2}=0.984\right)$, where the kinetics data was well-fitted using the pseudo-first order. Moreover, efficiency of catalysts was examined under solar light to achieve the sustainability.
\end{abstract}




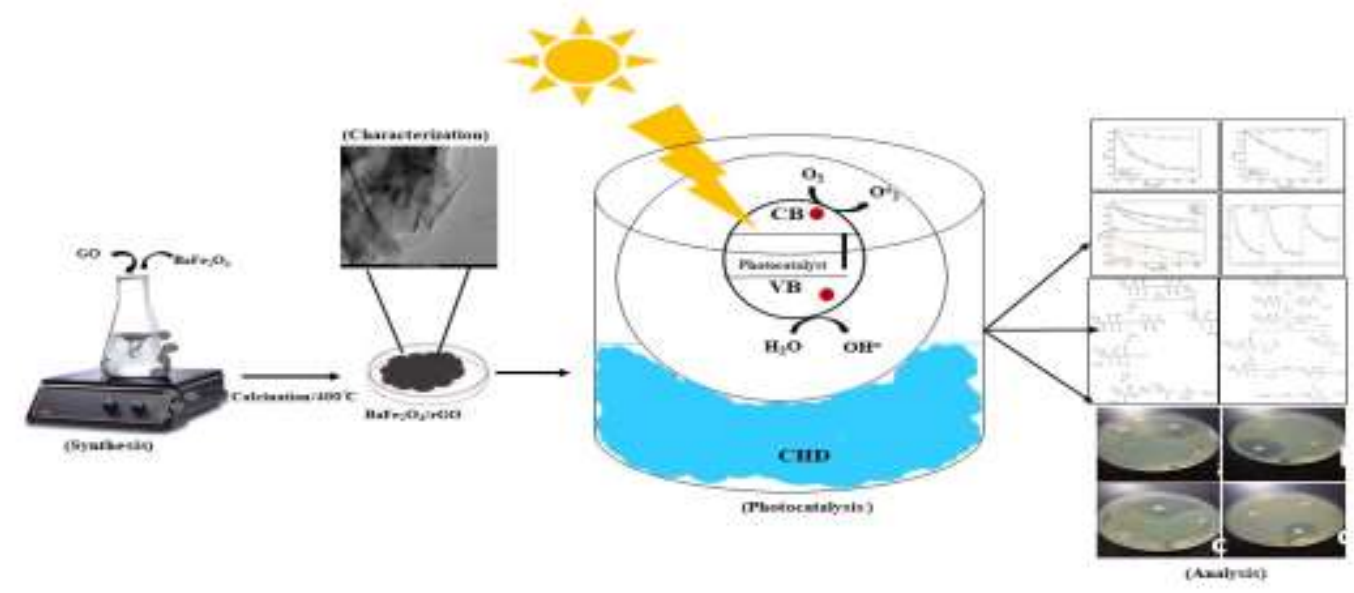

28

Keywords: Chlorhexidine Digluconate; $\mathrm{BaFe}_{2} \mathrm{O}_{4} / \mathrm{rGO}$; Adsorption combining Photocatalysis; Energy Efficiency

\section{Highlights}

- The adsorption and photocatalysis efficiency of $\mathrm{BaFe}_{2} \mathrm{O}_{4} / \mathrm{rGO}$ as catalyst displayed excellent degradation performance to CHD through $\pi-\pi$ stacking.

- Reduction in $\mathrm{UV}_{254}$ also confirmed that the mineralized end product by $\mathrm{BaFe}_{2} \mathrm{O}_{4} / \mathrm{rGO}$ has excellent degradation efficiency.

- Photogenerated electrons and Hydroxyl radicals was substantially responsible for CHD degradation.

- Toxicity of parent compound and its by-products reduces after photocatalysis process in $\mathrm{BaFe}_{2} \mathrm{O}_{4} / \mathrm{rGO}$ and possible pathway were established.

\section{Introduction}

Extensive research has focused on photocatalytic degradation of Personal Care Products (PCPs) due to their recalcitrant nature, nonbiodegradability, and unregulated disposal into aquatic bodies.These compounds, thus, negatively impact on both environment and human health (Das et al., 2014). Chlorhexidine Digluconate (CHD), which is a model compound, is broadly used as antiseptic among PCPs. It is commonly present in disinfectant, mouthwash formulations, toothpaste and cosmetics due to effectiveness against Gram-positive and Gram-negative bacteria (Sousa et al., 2017). CHD consist 
of two hexanes bonded ( $\mathrm{p}$-chlorophenyl) biguanides and its primary degradation product pchloroaniline act as a limiting factor for stabilizing the compound. However, overuse of these compound have been frequently detected in water bodies and are quickly absorbed/ metabolized as both hemotoxic and carcinogenic(Nidhi et al., 2011). Due to complex structure and bacteriostatic properties of CHD molecules, it can neither be completely removed through conventional treatment technologies from wastewater nor be biodegraded from the environment (Zwiener and Frimmel, 2000).

Thus, the development of efficient technologies are highly desired to remove PCPs and pharmaceuticals such as CHD from the aquatic ecosystem (Fidelis et al., 2019). Adsorption is an efficient and economical treatment for organic pollutant but with some limitations such as inefficient in complete degradation and leads to the secondary pollutant. Recently, graphene oxide (GO) with high surface area, strong functional group and conjugate $\pi$ region used as an adsorbent for organic pollutant removal (Zhang et al., 2016).Undoubtedly, adsorption process can only change the phase of the pollutant, cannot completely remove the organic pollutant. In addition, photocatalysis is an efficient and green technology for mineralization of recalcitrant organic pollutant with some advantages such as lack of secondary waste generation and easy implementation (Wang et al., 2021). Interestingly, studies showed that use of adsorption-photocatalysis simultaneously grab attention for efficient removal of organic pollutant due to recombination of electron-hole pair disadvantage of photocatalysis (Yuan et al., 2020). Various studies showed significant removal of antibiotics using adsorption-photocatalysis treatment such as ciprofloxacin (with $59.5 \%$ adsorption and $82.5 \%$ degradation in $60 \mathrm{~min}$ ), tetracycline (with 18\% adsorption and 70\% degradation in $90 \mathrm{~min}$ ), ofloxacin (with $93.4 \%$ adsorption and photocatalytic degradation in $30 \mathrm{~min}$ ) (Chen et al., 2020).Motivated by previous studies, Barium ferrites with exceptional magnetic and photocatalytic property used for synthesis of new material in order to develop the dual functioning material by combining the advantages of both adsorption-photocatalysis technologies (Roonasi and Mazinani, 2017a). As per the literature, barium ferrites have less been studied and can also be used for easy separation as well as strong visible light absorption capacity due to narrower band gap (Casbeer et al., 2012).

In this system, Response surface methodology (RSM) has been used to understand the interaction among the operating conditions ( $\mathrm{pH}$, catalyst dose and time) for optimization process, resulting in a good estimate of the optimum response $\mathrm{BaFe}_{2} \mathrm{O}_{4} / \mathrm{rGO}$ used as an adsorbent first in dark, and as photocatalyst under UV, visible and solar radiation. In addition, kinetic studies for removal of pollutant, mineralization rate (in terms of TOC) and reduction in aromaticity (in terms of $\mathrm{UV}_{254} / \mathrm{UV}_{280}$ ) during adsorption and photocatalysis has been carried out. Furthermore, possible mechanism for mineralization of pollutant via adsorption-photocatalysis was studied by trapping experiment and possible pathway was proposed, based on LC-MS analysis. For practical applicability, 
$\mathrm{BaFe}_{2} \mathrm{O}_{4} / \mathrm{rGO}$ photocatalyst used for the treatment of formulated wastewater in $\mathrm{UV}$, visible and solar radiation.

\section{Materials and Methods}

\subsection{Chemicals}

All the chemicals and reagent were procured by Sigma-Aldrich. They were of analytical grade and used without further purification. Microporous hydrophobic PTFE membrane with pore size around $0.45 \mu \mathrm{m}$ and $80 \%$ porosity was obtained from GE Osmonics Company.

\subsection{Syntheses of Graphene Oxide:}

For the present study, $1 \mathrm{~g}$ of graphite (Jodex England) was carefully added to the mixture of concentrated $\mathrm{H}_{2} \mathrm{SO}_{4}: \mathrm{H}_{3} \mathrm{PO}_{4}$ (prepared in a ratio of $4: 1$ by v/v). After the addition of graphite, the prepared solution was placed in an ice bath. Consequently, the experimentation was carried out at room temperature where the prepared mixture was stirred for $72 \mathrm{~h}$ using a rotary shaker. The process was carried out till the mixture's color changed to dark brown from dark purplish green. $\mathrm{H}_{2} \mathrm{O}_{2}$ was added to the mixture to halt the oxidation process, which further changed its colour to bright yellow. Moreover, remnant salts in the mixture were removed by adding of $10 \% \mathrm{HCl}$. The washing process for the experimentation followed a simple decantation of supernatant. It was observed that during the process of washing, the addition of deionized water caused exfoliation of GO, which thickens the solution due to the formation of GO gel. The obtained GO gel was further dried for $24 \mathrm{~h}$ at $70{ }^{\circ} \mathrm{C}$. The dried GO gel was then stored in a dry place for further experimentation (Aboubaraka et al., 2017).

\subsection{Synthesis of $\mathrm{BaFe}_{2} \mathrm{O}_{4} / r G O$}

A certain amount of Barium nitrate and iron $(2: 1 \mathrm{w} / \mathrm{w})$ were added into $100 \mathrm{~mL}$ beakers using distilled water at $60^{\circ} \mathrm{C}$. To this mixture, prepared graphene oxide was added in mass ratio of $1: 2 \mathrm{w} / \mathrm{w}$. Afterward, the resulting suspension kept at magnetic stirrer for homogeneous mixing. Then, the solution was filtered and ignited at a temperature of $400{ }^{\circ} \mathrm{C}$ for $30 \mathrm{~min}$. The resultant dark brown material was obtained and powdered into fine particle (Roonasi and Mazinani, 2017b).

\subsection{Characterization}

To prove the stability of prepared sample as a photocatalyst, following characterization were employed i) X-ray diffraction (XRD) was used for phase identification on a Bruker D8 ADVANCE diffractometer with $\mathrm{Cu}-\mathrm{K} \alpha(\lambda=1.5406 \AA)$ radiation, ii) Fourier transform infrared (FTIR) spectra was used to identify the presence of functional group on Bruker Vertex- 70 by diffused reflectance accessory technique, iii) morphology and structural observations were analyzed using Hitachi S-4300 
type field emission scanning electron microscope (FE-SEM) at an electron acceleration voltage of 1 $\mathrm{keV}$, iv) Energy-dispersive X-ray spectrometer (EDX) equipped on SEM was used to identify the chemical compositions and elemental mapping of the catalyst, v) UV-vis diffuse reflectance spectra (UV-DRS) was used for bandgap analysis using Perkin Elmer Lambda 900 spectrophotometer equipped with an integrated sphere $\left(\mathrm{BaSO}_{4}\right.$ was used as a reference material),and vi) X-ray photoelectron spectroscopy (XPS) was used to identify the oxidation state of compounds using a VG 250 Escalab spectrometer equipped with an $\mathrm{Al}$ anode $(\mathrm{Al}-\mathrm{K} \alpha=1486.7 \mathrm{eV})$ as an $\mathrm{X}$-ray source.

\subsection{Experimental Design using Response surface Methodology}

RSM was used to optimize three variables ( $\mathrm{s} / \mathrm{c}$ ratio, $\mathrm{pH}$ and time) with three different levels $(+1,0$ and -1) for maximum CHD removal as a response. The experimental design (DoE) was performed based on the Face Centred Central Composite Design (FCCD) devised by Design Expert v7.0.0 software (SaMeep 104, State Ease, INC. Minneapolia (USA). A total of 20 different combinations were obtained with six centre points in random order according to a Central Composite Design (CCD) configuration for three factors. In this analysis, Face Central Composite Design (FCCD) was used to model the percentage removal of CHD as a quadratic model. "Analysis of variance" (ANOVA), correlation coefficient $\left(\mathrm{R}^{2}\right)$, lack of fit, $\mathrm{CV} \%$ and adjusted coefficient of determination $\left(\mathrm{R}^{2}\right.$ adj $)$ were used for statistical validation.

\subsection{Adsorption experiments}

The adsorption kinetics has been performed for the adsorbent in dark condition at optimized condition. At a certain time- interval, suspension was collected and filtered through $0.45 \mu \mathrm{m}$ syringe filter. The residual concentration of CHD was measured in UV-vis spectrophotometer (Lab-tech, China). The adsorption capacity at equilibrium $(q)$ was determined as

$\mathrm{q}=\left(\mathrm{C}_{\mathrm{o}}-\mathrm{C}_{\mathrm{e}}\right) \mathrm{V} / \mathrm{m}$

where $C_{0}$ and $C_{\mathrm{e}}\left(\mathrm{mg} \mathrm{L}^{-1}\right)$ are the initial and equilibrium pollutant concentrations, respectively, $V$ represented the solution volume (L), and $m(\mathrm{~g})$ is the adsorbent mass.

The pseudo first-order kinetic model was given by:

$\ln \left(\mathrm{q}-\mathrm{q}_{\mathrm{t}}\right)=\ln \mathrm{q}-\mathrm{k}_{1} \mathrm{t}$

where $t$ is time, $q_{t}$ is adsorption capacity at time $t$, and $k_{1}$ is the pseudo-first-order rate constant.

The pseudo-second-order kinetic model was given by:

$$
\frac{\mathrm{t}}{\mathrm{q}_{\mathrm{t}}}=\frac{\mathrm{t}}{\mathrm{q}}-\frac{1}{\mathrm{k}_{2} \mathrm{q}^{2}}
$$


where $k_{2}$ is the pseudo-second-order rate constant.

\subsection{Photocatalytic activity test}

The photocatalysis activity during CHD degradation was monitored in a lab-scale photoreactor under UV light (PMI, India). The source of light provided by a UVC-lamp (11W, Phillip, intensity-44.4 $\mathrm{mW} . \mathrm{cm}^{-2}$ ) and visible lamp (200W, intensity- $40 \mathrm{~mW} . \mathrm{cm}^{-2}$ ) and natural light (intensity -50-60 $\mathrm{mW} . \mathrm{cm}^{-2}$ ) was measured by a radiometer (Delta OHM, LP-NET14). The dispersion of catalyst in a $500 \mathrm{~mL}$ solution of CHD (30 ppm) was injected into the photoreactor with aeration and operational condition ( $\mathrm{pH}$ range 6-10, S/C ratio 1.01-3.0 and Time 10-60 min.). This experiment tracked and analysed the residual CHD in the reaction mixture as a function of time. To check the experimental results' reproducibility, all the experimental runs were repeated three times. Where, one-hour batch study was conducted with sample collection at a 5-minute interval. An aliquot was centrifuged $\left(4^{\circ} \mathrm{C}\right.$, $11,000 \mathrm{X} g, 5 \mathrm{~min}$.) and the supernatant was collected for subsequent analyses.

\subsection{Kinetic study of CHD degradation}

Calculating oxidant and reductant in solution is nearly impossible. Thus, the kinetic pseudo-first-order model has been carried out to study the modeling CHD degradation Eqs (4) \& (5).

$\ln \frac{C_{t}}{C_{O}}=-K_{o b s} t$

$r_{o b s}=-k_{o b s} C_{C H D}$

Where, $K_{o b s}$ (Rate constant of reaction) was calculated from the slope by plotting a graph between $\ln \frac{C_{t}}{C_{o}}$ versus $\mathrm{t}$ and $r_{o b s}$ is the observed CHD degradation rate $\left(\mathrm{mg} \mathrm{L}^{-1} \mathrm{~min}\right)$ in the photoreactor. In the above equations, the reaction rate constant $\left(K_{o b s}\right)$ can be either negative or positive. Noticeably, " $K_{o b s}$ " does not include the concentration as these parameters are taken into consideration (Nasseh et al., 2018).

\subsection{Analytical Method}

UV-vis spectrophotometer (Lab-tech, China) was used to measure the Ultraviolet (UV) absorbance at $254 \mathrm{~nm}, 280 \mathrm{~nm}$ and residual CHD concentration in the reaction mixture were measured at $275 \mathrm{~nm}$ upon the specification of spectral indices. TOC analyzer (Shimandzu 5000) was used to determine the reduction of organic content and mineralization of CHD. LC-MS analysis (Thermo Scientific TSQ 8000 liquid chromatograph-mass spectrometer) has been carried out to investigate the degradation products of CHD. 


$$
E_{E O}=\frac{P \times t \times 1000}{V \times 60 \times \log \frac{C_{i}}{C_{f}}}
$$
volume (L) of the sample.

\section{Results and discussion}

$$
\mathrm{E}_{\mathrm{g}}(\mathrm{eV})=\frac{1240}{\lambda_{\mathrm{g}}} \mathrm{nm}
$$

The figure-of-merit electrical energy per order (EEO) is useful for evaluating electrical energy consumption in photocatalytic degradation of organic contaminants, as per International Union of Pure and Applied Chemistry (IUPAC). EEO defined as amount of electrical energy consumed (kWh) during photocatalytic degradation of fixed volume of organic pollutant (Azarpira et al., 2019).

Where $\mathrm{P}$ is the power rate $(\mathrm{kW})$ of the photocatalytic system, $\mathrm{t}$ is the irradiation time (min), $\mathrm{V}$ is the

\subsection{Bacterial susceptibility test for CHD degradation and photo mineralized product}

A bacterial susceptibility test was carried out on anaerobic gram-positive bacteria (Bacillus cereus) to evaluate the potential for aquatic toxicity of treated and untreated CHD containing water. The susceptibility test was carried out by autoclaving agar media of Muller Hinton, and Petri plates at 66.8Pa and $121{ }^{\circ} \mathrm{C}$ for $20 \mathrm{~min}$. Approximately $1 \mathrm{ml}$ of cultural broth suspension of Bacillus cereus were mixed in a media. Homogeneously mixed cultural suspension of bacteria and media shows a confluent lawn of growth on incubation. The incubation period for bacterial growth was carried out for $24 \mathrm{hr}$ at $37^{\circ} \mathrm{C}$ prior to observation of the inhibition zone.

\subsection{Characterization of the synthesized photocatalyst}

The synthesized catalysts were characterized to know the bandgap, surface morphology, elemental analysis, and crystallinity. UV-vis diffuse reflectance spectroscopy was used to determine optical absorbance property of prepared sample and their light-harvesting nature in the wavelength visible range (200-800 nm). Both the $\mathrm{GO}$ and $\mathrm{BaFe}_{2} \mathrm{O}_{4} / \mathrm{rGO}$ can absorb visible light but $\mathrm{BaFe}_{2} \mathrm{O}_{4} / \mathrm{rGO}$ shows strong absorption in visible range due to the shifting of red absorption peak and low bandgap energy was calculated using the following formula:

Where $\lambda_{g}$ is the wavelength value obtained from UV-DRS spectra. The bandgap energy has been calculated from Tauc plot of absorbance data (Fig.1c), which show the improvement of the photocatalytic performance of both synthesized photocatalyst ( $\mathrm{GO}$ and $\mathrm{BaFe}_{2} \mathrm{O}_{4} / \mathrm{rGO}$ ). The lowering of band energy in $\mathrm{GO}(2.89 \mathrm{eV})$ and $\mathrm{BaFe}_{2} \mathrm{O}_{4} / \mathrm{rGO}(1.86 \mathrm{eV})$ showed that the synthesis process has been achieved successfully. DRS results of GO revealed the absorption peak of $\pi \rightarrow \pi^{*}$ transition of C- 
$\mathrm{C}$ bonds around $210-203 \mathrm{~nm}$ along with another peak of $\mathrm{n} \rightarrow \pi^{*}$ transition of $\mathrm{C}-\mathrm{O}$ bonds around 300$320 \mathrm{~nm}$. However, in $\mathrm{BaFe}_{2} \mathrm{O}_{4} / \mathrm{rGO}, \pi \rightarrow \pi^{*}$ transition peak has been shifted around 260-270 nm demonstrating the restoration of electronic conjugation on functionalization of GO. Therefore, $\mathrm{BaFe}_{2} \mathrm{O}_{4} / \mathrm{rGO}$ can effectively improve the light absorption properties of $\mathrm{GO}$, for visible range as well.

Fig. 1: a) XRD patterns; b) FTIR spectra and c) UV-vis diffuse reflectance spectra of GO and $\mathrm{BaFe}_{2} \mathrm{O}_{4} / \mathrm{rGO}$.

FTIR spectrum was recorded to verify the successful synthesis of photocatalyst. Compared the spectrum of pure $\mathrm{GO}$ and $\mathrm{BaFe}_{2} \mathrm{O}_{4} / \mathrm{rGO}$, the $\mathrm{GO}$ (Fig.1b) shows the characteristic peaks around 1734 $\mathrm{cm}^{-1}$ (due to the presence of $-\mathrm{COOH}$ ), $1580 \mathrm{~cm}^{-1}$ (C=C vibration form graphitic domain), $1375 \mathrm{~cm}^{-1}$ ($\mathrm{C}-\mathrm{OH}$ ), $1232 \mathrm{~cm}^{-1}$ (C-O stretch) and $1050 \mathrm{~cm}^{-1}$ (epoxide groups), respectively. These patterns further confirm the presence of oxygen containing functional group of GO. Furthermore, a broad and less intense peak in the region around $3500-3000 \mathrm{~cm}^{-1}$ was also observed due to stretching vibrations of hydroxyl group from absorbed water molecules or phenolic $\mathrm{OH}$ or $\mathrm{OH}$ from carboxylic groups in GO.As for $\mathrm{BaFe}_{2} \mathrm{O}_{4} / \mathrm{rGO}$ (Fig.1b), the characteristic peaks of oxygen-containing functional groups of GO disappear and single sharp peak appeared at band $1420.31 \mathrm{~cm}^{-1}$ reveals the metal-oxygen characteristic (Roonasi and Mazinani, 2017a) and reduction of GO to rGO occurred. By comparing the two curves ( $\mathrm{GO}$ and $\mathrm{BaFe}_{2} \mathrm{O}_{4} / \mathrm{rGO}$ ), it was found that the characteristic peaks of $\mathrm{GO}$ are weakened in $\mathrm{BaFe}_{2} \mathrm{O}_{4} / \mathrm{rGO}$ and confirmed the synthesis was done successfully (Sonal et al., 2020). Diffusion peaks from XRD analysis of GO (Fig.1a), was found at $2 \theta=10.46$ (001) with d-spacing of $0.850 \mathrm{~nm}$ due to the oxidation of graphite. The published studies suggested that the characteristic peak of graphite found at $2 \theta=26.58^{\circ}$ (002) would disappeared due to the addition of oxygen-containing functional group (Aboubaraka et al., 2017). Thus, suggesting that GO was successfully synthesized. In addition, the intensity and sharp diffraction peak was observed at $2 \theta=32^{\circ}$ with interlayering spacing $0.27 \mathrm{~nm}$ indicating the presence of metal on the surface of carbon (Roonasi and Mazinani, 2017a). Besides this peak, characteristic peak of GO at $2 \theta=10.46$ was disappeared and a weak peak found at $2 \theta=28.43^{\circ}$, corresponding to coexistence of $\mathrm{Ba}^{2+}$ on the surface of GO in $\mathrm{BaFe}_{2} \mathrm{O}_{4} / \mathrm{rGO}$ (Fig.3a) (Roonasi and Mazinani, 2017a). Therefore, the results from XRD analysis confirmed the crystallographic nature of material and the coexistence of $\mathrm{Ba}^{2+}$ and GO. XPS data used to detect the chemical constituents of $\mathrm{GO}$ and $\mathrm{BaFe}_{2} \mathrm{O}_{4} / \mathrm{rGO}$. The corresponding peaks of $\mathrm{C} 1 \mathrm{~s}, \mathrm{O} 1 \mathrm{~s}, \mathrm{Ba}\left(3 \mathrm{~d}_{5 / 2}\right),\left(3 \mathrm{~d}_{3 / 2}\right)$ and $\mathrm{Ba}(4 \mathrm{~d})$ were identified in both the sample. More specifically, high-resolution of C 1s spectra of GO showed peaks at 284.6, 285.3, 288.0, and $289.2 \mathrm{eV}$ (Fig.2), which correspond to $\mathrm{C}-\mathrm{O}$ and $\mathrm{C}=\mathrm{O}$ bonds respectively (Bai et al., 2018). Additionally, with the formation of $\mathrm{BaFe}_{2} \mathrm{O}_{4} / \mathrm{rGO}$, band energies of $\mathrm{C}$ (1s) was decreased approximately to $284.68 \mathrm{eV}$, indicating reduction of oxygen-containing functional group and confirming the transformation of GO to rGO with the doping on $\mathrm{sp}^{2}$ carbon atom of GO (Hu et al., 2020). Similarly, peak of O 1 s found at 
$532.86 \mathrm{eV}$ is attributed to the lattice of $\mathrm{O}$ or $-\mathrm{OH}$ group on the surface of $\mathrm{GO}$, respectively (Hu et al., 2020).While, $\mathrm{O} 1 \mathrm{~s}$ core level spectrum of $\mathrm{BaFe}_{2} \mathrm{O}_{4} / \mathrm{rGO}$ was deconvoluted at $530.68 \mathrm{eV}\left(\mathrm{BaCO}_{3}\right)$, suggesting the presence of $\mathrm{Ba}^{2+}$ on the surface of GO (Han et al., 2021). This shifting of band energies shows the interaction of $\mathrm{GO}$ and $\mathrm{BaFe}_{2} \mathrm{O}_{4}$ and their influence on the hydroxyl oxygen of the surface. Evidently, the double peak of $\mathrm{Ba}\left(3 \mathrm{~d}_{5 / 2}\right),\left(3 \mathrm{~d}_{3 / 2}\right)$ and $\mathrm{Ba}(4 \mathrm{~d})$ appeared at binding energies of 779.60 $\mathrm{eV}, 794.90 \mathrm{eV}$ and $89.84 \mathrm{eV}$, respectively on the surface of $\mathrm{C} 1 \mathrm{~s}$, indicated the successful formation of $\mathrm{BaFe}_{2} \mathrm{O}_{4} / \mathrm{rGO}$ (Fig.2) (Han et al., 2021).

Fig 2: a) Full scan spectra and extended high-resolution b) C 1s; c) O 1s and d) Ba 3d spectra of GO and $\mathrm{BaFe} 2 \mathrm{O} 4 / \mathrm{rGO}$

The surface and structural morphological were investigated by SEM and high-resolution TEM (HRTEM). As shown in Fig.3a-e, GO consist of the two-dimensional, grooved and undulated sheetlike structure due to deformation upon exfoliation and restacking of graphite. This inner layering of GO occurs due to the presence of oxygen-containing functional groups such as carboxyl, epoxy and hydroxyl group was also supported by FTIR analysis. While, $\mathrm{BaFe}_{2} \mathrm{O}_{4} / \mathrm{rGO}$ (Fig.3f-m) have smooth sheet like morphology with more corrugations as compared to the GO. The elemental analysis confirmed the presence of $\mathrm{C}, \mathrm{O}$ and $\mathrm{Ba}$ in the samples with other adhering impurities and also proved the successful introduction of Ba in GO (Aboubaraka et al., 2017; El-Sheikh et al., 2017; Wang et al., 2012). In addition, TEM images and elemental mapping of prepared photocatalyst confirmed the uniform distribution of $\mathrm{C}, \mathrm{O}, \mathrm{Fe}$ and $\mathrm{Ba}$ throughout the material.

Fig 3: SEM, TEM and EDS images of photocatalysts (a-e) GO; and (f-m) $\mathrm{BaFe}_{2} \mathrm{O}_{4} / \mathrm{rGO}$.

The BET surface area of GO and $\mathrm{BaFe}_{2} \mathrm{O}_{4} / \mathrm{rGO}$ are $93.6666 \mathrm{~m}^{2} \mathrm{~g}^{-1}$ and $91.50 \mathrm{~m}^{2} \mathrm{~g}^{-1}$, respectively. A large surface area is widely believed to be needed for high photocatalytic process. In contrast, $\mathrm{BaFe}_{2} \mathrm{O}_{4} / \mathrm{rGO}$ possess low surface area as compared to GO but shows high photocatalytic activity. The possible reason was the presence of potential reactive sites and shortening of mass transfer distance, enhance the adsorption and photocatalytic process (Zhu et al., 2018).

Therefore, this characterization studies suggested that use of $\mathrm{GO}$ and $\mathrm{BaFe}_{2} \mathrm{O}_{4} / \mathrm{rGO}$ proved as efficient photocatalyst because various oxygen-containing functional group participates in redox reaction and polyaromatic $\pi$-system of $\mathrm{GO}$ and $\mathrm{BaFe}_{2} \mathrm{O}_{4} / \mathrm{rGO}$ reacts with the aromatic rings of CHD in wastewater by either $\pi-\pi$ stacking interactions or strong hydrophobic effect make them highly efficient adsorbent materials as well (Thakur and Kandasubramanian, 2019).

\subsection{Regression analysis for the photocatalytic activity of photocatalyst on CHD removal}

A polynomial model was used to represent the effects of individual parameters as well as their synergistic interactive effects on the response variable in Eq. (8)-(9). 
CHD removal \% $\left(\mathrm{BaFe}_{2} \mathrm{O}_{4} / \mathrm{rGO}\right)=44.67-1.51 \mathrm{X}_{1}+9.67 \mathrm{X}_{2}+3.52 \mathrm{X}_{3}-1.81 \mathrm{X}_{1} \mathrm{X}_{2}-0.043 \mathrm{X}_{1} \mathrm{X}_{3}$ $-0.3 \mathrm{X}_{2} \mathrm{X}_{3}-11.99 \mathrm{X}_{1}^{2}-3.29 \mathrm{X}_{2}^{2}-1.64 \mathrm{X}_{3}^{2}$

293

294

295

296

297

298

299

300

301

302

303

304

305

306

307

308

309

310

311

312

313

314

315

316

317

318

319

320

321

322

323

The results of ANOVA (Table 1) represent the suitable model for photocatalysts during photocatalysis process. The P-value of the model, for the photocatalysts, was <0.0001, and the F-value was 27.27 and 63.49 for $\mathrm{GO}$ and $\mathrm{BaFe}_{2} \mathrm{O}_{4} / \mathrm{rGO}$, respectively. These results confirmed that the model was highly significant, which is supported by the close agreement between the predicted and observed values (Fig.S1: A-B in supplementary material). The $\mathrm{R}^{2}$ values were obtained 0.9609 and 0.9828 for $\mathrm{GO}$ and $\mathrm{BaFe}_{2} \mathrm{O}_{4} / \mathrm{rGO}$, respectively, which implies high correlation between actual and predicted values for CHD removal and further confirmed the reliability of model (Sonal et al., 2018). Smaller P > F (< 0.05) values show the significance of the certain model and the higher contribution towards the response variable, while the higher P-value indicates the insignificance of the model.

Table 1: ANOVA Analysis for the catalytic activity of the different photocatalyst

\subsection{Adsorption and Photocatalytic performance of prepared photocatalysts}

Comparison of adsorption in dark condition, photolysis and photocatalysis were carried out at RSM optimized condition (Fig.4). Adsorption studies were carried out in dark condition and remarkable results was observed with adsorption equilibrium at $80 \mathrm{~min}$ and $60 \mathrm{~min}$ for $\mathrm{GO}$ and $\mathrm{BaFe}_{2} \mathrm{O}_{4} / \mathrm{rGO}$, respectively. Kinetics studies of different sample demonstrated a pseudo- second order model is better fitted with experimental and calculated results. Adsorption capacities of $\mathrm{BaFe}_{2} \mathrm{O}_{4} / \mathrm{rGO}$ and $\mathrm{GO}$ are $303.3 \mathrm{mg} / \mathrm{g}$ (within $60 \mathrm{~min}$ ) and $200 \mathrm{mg} / \mathrm{g}$ (within 80min), respectively. The adsorption capacity of GO enhanced by addition of $\mathrm{BaFe}_{2} \mathrm{O}_{4}$, resulted in increased surface area in $\mathrm{BaFe}_{2} \mathrm{O}_{4} / \mathrm{rGO}$ as determined by BET. However, above result indicated that $\mathrm{BaFe}_{2} \mathrm{O}_{4}$ loading was beneficial for adsorption of CHD as representative of organic pollutant. This is due to the electrostatic interaction, $\pi-\pi$ stacking and more disorder region in $\mathrm{BaFe}_{2} \mathrm{O}_{4} / \mathrm{rGO}$ than GO (Singh et al., 2018). Point zero charge of $\mathrm{GO}$ (6.0) and $\mathrm{BaFe}_{2} \mathrm{O}_{4} / \mathrm{rGO}$ (4.8) (Fig.S2), this may be due to the presence of carboxyl group and metal-oxygen group in $\mathrm{GO}$ and $\mathrm{BaFe}_{2} \mathrm{O}_{4} / \mathrm{rGO}$. Highest degradation rates were observed, when solution $\mathrm{pH}$ was equal to alkaline condition due to the electrostatic interaction occur among cationic nature of CHD and positively charged photocatalyst. Thus, adsorption occurs due to the electrostatic interaction of pollutant on the surface of photocatalysts, making good agreement for adsorption of antibiotics.

Fig 4: a) Adsorption of CHD at optimized condition; b) pseudo-first order model; and c) pseudosecond order model for $\mathrm{GO}$ and $\mathrm{BaFe}_{2} \mathrm{O}_{4} / \mathrm{rGO}$ 
In addition, agglomeration and surface hydrophobicity are the major limitation for modification of GO and several researches were conducted to modified surface of GO via doping, fabrication, or immobilization for improvisation of these shortcomings. Therefore, grafting of $\mathrm{Ba}^{2+}$ on the surface of GO aimed to realize separation, dispersity, high antibiotics adsorption capacity (Li et al., 2019).

The photodegradation efficiency of both materials were compared under visible light irradiation for CHD (Fig.5a). First, blank experiment (photolysis) was performed in visible-light (370-420 nm) and slight degradation of CHD (10\%). The adsorption-desorption equilibrium experiment was carried out in dark for stability of the photocatalytic reaction. It was observed that photocatalyst showed negligible degradation in absent of light. Moreover, it was found that the increased adsorption efficiency could also be favourable for photocatalytic activity i.e., GO (88.17\%) and $\mathrm{BaFe}_{2} \mathrm{O}_{4} / \mathrm{rGO}$ (93.95\%) for CHD removal. Since, adsorption process decreased the mass transfer distance among pollutant and photocatalyst. Meanwhile, narrow band-gap energy, homogeneous dispersion, and excellent electrical conductivity leading to the significant interaction of $\mathrm{d}-\mathrm{d}$ (from $3 \mathrm{~d}$ orbital of $\mathrm{Ba}$ ions) and $\mathrm{d}-\pi$ transitions (aromatic rings of CHD molecules) under visible-light formed by photogenerated carrier with short time and pollutant. Additionally, pseudo-first order (PFO) kinetics was in good agreement with reaction rate constant $0.954(\mathrm{GO})$ and $1.14\left(\mathrm{BaFe}_{2} \mathrm{O}_{4} / \mathrm{rGO}\right)$, respectively. While corelation coefficient of the model (PFO) are $0.937(\mathrm{GO})$ and $0.984\left(\mathrm{BaFe}_{2} \mathrm{O}_{4} / \mathrm{rGO}\right)$, respectively i.e. closer to 1 .

Reusability test carried out to investigate the large-scale applicability of photocatalyst as an industrial use. The rate of $\mathrm{CHD}$ degradation by $\mathrm{BaFe}_{2} \mathrm{O}_{4} / \mathrm{rGO}$ decreased after 4 cycles, indicating that $\mathrm{BaFe}_{2} \mathrm{O}_{4} / \mathrm{rGO}$ possessed good reusability.

Thus, above results suggested the $\mathrm{BaFe}_{2} \mathrm{O}_{4} / \mathrm{rGO}$ showed optimal balance for adsorption and photocatalytic process as compared to the GO and also considered as durable photocatalyst.

Fig 5: a) Photocatalytic degradation of $\mathrm{CHD}$ at optimized condition; b) pseudo-first order kinetics; c) trapping experiment of active species; and d) reusability experiment of $\mathrm{GO}$ and $\mathrm{BaFe} 2 \mathrm{O} 4 / \mathrm{rGO}$ mediated photocatalytic degradation of CHD.

\subsection{Probable mechanism for CHD degradation}

Charge separations occur on the surface of photocatalysts ( $\mathrm{GO}$ and $\mathrm{BaFe}_{2} \mathrm{O}_{4} / \mathrm{rGO}$ ) by exposure of visible-light irradiation. The photogenerated electron and photogenerated holes migrates to the surface of photocatalyst, where they participate in redox reaction for degradation of targeted pollutant. As photodegradation efficiency of photocatalyst is related to the contribution of its active radicals (Fig.5c). A series of trapping experiments were carried out and isopropanol (IPA) (1\%), $1.0 \mathrm{mM}$ of potassium persulfate $\left(\mathrm{K}_{2} \mathrm{~S}_{2} \mathrm{O}_{8}\right)$ and ethylenediaminetetraacetic acid (EDTA) were used as scavengers of hydroxyl radicals $\left({ }^{\circ} \mathrm{OH}\right)$, electron $\left(\mathrm{e}^{-}\right)$, and holes $\left(\mathrm{h}^{+}\right)$respectively. The photocatalytic efficiency of 
GO and $\mathrm{BaFe}_{2} \mathrm{O}_{4} / \mathrm{rGO}$ was reduced by addition of IPA and $\mathrm{K}_{2} \mathrm{~S}_{2} \mathrm{O}_{8}$ and insignificant change was observed on EDTA addition. However, ${ }^{\circ} \mathrm{OH}$ and $\mathrm{e}^{-}$actively participate in photocatalytic degradation of $\mathrm{CHD}$ in $\mathrm{GO}$ and $\mathrm{BaFe}_{2} \mathrm{O}_{4} / \mathrm{rGO}$ mediated photocatalytic reaction but $\mathrm{h}^{+}$has insignificant effect, respectively. The removal rate reduced from $88.17 \%$ to 67.44 (IPA),55.81(EDTA) in the case of GO mediated photocatalysis process, while in $\mathrm{BaFe}_{2} \mathrm{O}_{4} / \mathrm{rGO}$ mediated photodegradation of $\mathrm{CHD}$ decreased rapidly from $93.95 \%$ to $75.19 \%$ (IPA) and $63.56 \%$ (EDTA), respectively. This result indicates that IPA and $\mathrm{K}_{2} \mathrm{~S}_{2} \mathrm{O}_{8}$ inhibited the CHD degradation and further confirms that ${ }^{\circ} \mathrm{OH}$ and $\mathrm{e}^{-}$ was dominating reactive species. Above result speculated the effect of photogenerated reactive species decreased in order of $\mathrm{e}^{-}>{ }^{\circ} \mathrm{OH}>\mathrm{h}^{+}$.

The photogenerated electron (valance band) and holes (conduction band) participate in redox reaction, where holes may react with water molecules or $\mathrm{OH}^{-}$to produce ${ }^{\circ} \mathrm{OH}$ and photogenerated electron at conduction band may reacts with oxygen to produce superoxide radical anions $\left(\mathrm{O}_{2}{ }^{-}\right)$(Fig.5c). As CHD (cationic in nature) reacts with ${ }^{\circ} \mathrm{OH}$ and $e^{-}$, then oxidation process takes place in degradation of pollutant.

Performance and application of the any catalyst depends on degradation and mineralization of the targeted compound into nontoxic smaller molecules. Therefore, it is important to understand the CHD degradation to $88.17 \%(\mathrm{GO})$ and $93.95 \%\left(\mathrm{BaFe}_{2} \mathrm{O}_{4} / \mathrm{rGO}\right)$ by:

a) TOC determination, which shows the relationship between mineralization of pollutant and b) formation of its by-products. The TOC values were reduced to $79.21 \%$ and $88.14 \%$ for GO and GO$\mathrm{BaFe}_{2} \mathrm{O}_{4} / \mathrm{rGO}$, respectively showing the extent of mineralization taking place in the reaction solution (Fig.6a). Difference in the values of TOC reduction and degradation of CHD, reflects the presence of carbon atom as by-products in treated water (Chen et al., 2020). This result supported with reduction in hydrophobic compound and conversion of heteroatoms such as chlorine or nitrogen into inorganic anions in solution was also determined to investigate the photocatalytic efficiency of catalysts. $U_{254}$ is the crucial parameter to determine the cleavage of aromatic $\mathrm{C}=\mathrm{C}$ in solution after photocatalysis process. Thus, reduction in the value of aromatic $\mathrm{C}=\mathrm{C}$ content present in $\mathrm{CHD}$ with respect to time was measured at $254 \mathrm{~nm}$ in UV-Spectroscopy (Priya et al., 2018). UV $_{254}$ reduction was ranging from 1.369 to 0.668 and 0.397 for $\mathrm{GO}$ and $\mathrm{BaFe}_{2} \mathrm{O}_{4} / \mathrm{rGO}$, respectively. This reduction is stoichiometrically close to the removal percentage of hydrophobic compound using (GO) $57.19 \%$ and $71.09 \%$ $\left(\mathrm{BaFe}_{2} \mathrm{O}_{4} / \mathrm{rGO}\right)$ (Fig.6b). Hence, $\mathrm{UV}_{254}$ reduction confirm the breakdown of long chain carbon atoms into smaller molecules. But $57.19 \%$ in GO mediated treatment indicates that breakdown of CHD into transformed product i.e.p-chloroaniline validated by LC/MS has adverse effect on aquatic life than parent compound .Similarly, inorganic ions production and TOC reduction supports the results of $\mathrm{UV}_{254}$ reduction. From this, it could be hypothesized that oxidative mechanism of photocatalysis process participate in cleavage of the aromatic ring of CHD molecules (Schneider et al., 2014). 
Therefore, result showed that $\mathrm{GO}$ and $\mathrm{BaFe}_{2} \mathrm{O}_{4} / \mathrm{rGO}$ also has immense potential to reduce aromaticity of the solution.

The overall reaction during photo mineralization of CHD in the excess of oxygen under optimized experimental condition is validated by the equation given below:

$$
\mathrm{C}_{34} \mathrm{H}_{54} \mathrm{Cl}_{2} \mathrm{~N}_{10} \mathrm{O}_{7}+36 \mathrm{O}_{2}+\mathrm{hv}(370-400 \mathrm{~nm}) \rightarrow 34 \mathrm{CO}_{2}+10 \mathrm{NH}_{3}+2 \mathrm{HCl}+11 \mathrm{H}_{2} \mathrm{O}
$$

Besides the TOC and aromaticity reduction, in order to explicate the route of CHD conversion into intermediates of the reaction, the sample was subjected to various experimental condition concerning i) the presence of chloride ion in the reaction mixture, ii) release of attached nitrogen into ammonia ion.

Fig 6: a) TOC removal and b) UV absorbance reduction in $\mathrm{GO}$ and $\mathrm{BaFe}_{2} \mathrm{O}_{4} / \mathrm{rGO}$ mediated photocatalytic degradation of CHD at optimized condition.

The initial concentration-time profiles of chloride anion and inorganic nitrogen $\left(\mathrm{NH}_{4}^{+}\right)$for photocatalytic system shows significant conversion of organic chlorine to chloride anion in GO and $\mathrm{BaFe}_{2} \mathrm{O}_{4} / \mathrm{rGO}$ mediated CHD removal. It was observed that there was a formation of approximately, $0.7748 \mathrm{mg} / \mathrm{L}$ and $0.7814 \mathrm{mg} / \mathrm{L}$ chloride ion respectively, in the reaction matrix of $\mathrm{GO}$ and $\mathrm{BaFe}_{2} \mathrm{O}_{4} / \mathrm{rGO}$ treated water. A similar trend was also observed for the attached nitrogen where,

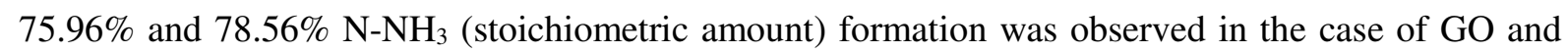
$\mathrm{BaFe}_{2} \mathrm{O}_{4} / \mathrm{rGO}$ treated wastewater, respectively.

b) Secondly, bacterial susceptibility test was carried out regarding the toxicity of intermediate. For toxicological studies of intermediate compound targeted microorganism was Bacillus cereus, which is commonly residing in human oral cavities was subjected to antimicrobial susceptibility test for toxicity investigation of the intermediate compound. Kirby-Bauer Disk Diffusion method was used to demonstrate toxicological results of the degraded compound. The zone of inhibition (measured in millimetres) of the treated sample through photocatalysts were observed on their respective plates. The diameter of the inhibition zone related to the susceptibility of Bacillus cereus and the diffusion rate of pure sample to the antibiotics such as amoxicillin and ciprofloxacin through agar media. Inhibition zone of a standard solution of CHD, $30 \mathrm{mg} / \mathrm{L}$ concentration of sample, ciprofloxacin and amoxicillin antibiotics was $30 \mathrm{~mm}, 15 \mathrm{~mm}, 50 \mathrm{~mm}$ and $3 \mathrm{~mm}$ in diameter (Fig.S3). Negligible inhibition zone was observed for the degraded product after photocatalytic degradation of CHD. The pattern of inhibition zone found after preliminary toxicological test on microorganisms without any preclinical analysis of CHD, illustrates the superiority of antimicrobial activity of pure CHD over ciprofloxacin and amoxicillin. From toxicological studies, it was observed that disposal of treated 
water into the environment was non-toxic in nature or unlikely to cause any harmful effect on the aquatic ecosystem.

Hence, formation of these mineralized products as well as degradation rate of CHD indicates the extent of true mineralization process. Higher degradation of CHD was achieved using $\mathrm{BaFe}_{2} \mathrm{O}_{4} / \mathrm{rGO}$ as compared to GO, this could be due to the dispersion of photocatalyst in water and enough availability of active site to irradiate through visible light led to the generation of enough ${ }^{\circ} \mathrm{OH}$ for noticeable mineralization of CHD. This stoichiometrically estimated values of formed chloride anion is close to the chlorine attached to the ring of CHD in untreated water $(1.438 \mathrm{mg} / \mathrm{L})$. Therefore, this estimation degraded products such as chloride ion or nitrogen moieties validates the mineralization of CHD by chloride ion formation.

In this context, degraded product analysis was carried out by LC-MS spectroscopy. Spectral peaks reflect the main intermediate formed during degradation of $\mathrm{CHD}$ and thus the toxicological investigation of degraded products has been carried out. The spectral reflection of pure chlorhexidine at 505 and $507 \mathrm{~m} / \mathrm{z}$ shows two isotopes of $\mathrm{Cl}$ atoms (35 and 37) present in the structure.

Whereas in case of GO, fragmentation of the parent molecules into smaller molecules represented by spectral peak $(\mathrm{m} / \mathrm{z}=127)$ with some noise shows the reduced number of byproducts, confirming 75 $79 \%$ of the mineralization process. In $\mathrm{BaFe}_{2} \mathrm{O}_{4} / \mathrm{rGO}$ mediated photocatalytic degradation, fragmentation of CHD into intermediates represented by one minor peaks $(\mathrm{m} / \mathrm{z}=149)$ with reduced number of intermediates (Table 2). A possible pathway for degradation of CHD by catalysts was proposed and breakdown of biguanide moiety found as a major contributor for the mineralization of CHD. Due to the breakdown of biguanide moiety, hydrolytically sensitive group of CHD involves the hydration and subsequent cleavage of $\mathrm{C}=\mathrm{N}$ bond which leads to the conversion of parent compound to transformed products. In addition, quantification and mass identification of transformed product are beyond the scope of study and would hopefully be addressed in a future study.

Table 2: LCMS Analysis of GO and $\mathrm{BaFe}_{2} \mathrm{O}_{4} / \mathrm{rGO}$ mediated photocatalytic degradation of CHD.

\subsection{Evaluation of photocatalytic efficiency of catalysts in $U V$ and solar treatment.}

To evaluate the efficiency of photocatalyst with ultimate goal of solar treatment for removal of organic pollutant. For this purpose, $\mathrm{GO}$ and $\mathrm{BaFe}_{2} \mathrm{O}_{4} / \mathrm{rGO}$ were used for $\mathrm{CHD}$ removal under solar as well as UV-light. First, photodegradation were carried out under the UV-irradiation and solar light at RSM optimized condition for the sake comparison with visible-treatment (Wang et al., 2019). These results justify the remarkable potential of photocatalysts for degradation of CHD using solar light to maintain the sustainability. The removal efficiency of $\mathrm{GO}$ and $\mathrm{BaFe}_{2} \mathrm{O}_{4} / \mathrm{rGO}$ for CHD degradation under solar irradiation in terms of UV absorbance and TOC showed in (Table 3). The results highlighted the superior performance under UV light as compared to solar as well as visible. Thus, solar possess combination of UV and visible was beneficial to accelerate the removal of such 
recalcitrant pollutant. Energy consumption and economics are of paramount importance for treatment technologies.

Table 3: Comparison of CHD degradation using $\mathrm{GO}$ and $\mathrm{BaFe}_{2} \mathrm{O}_{4} / \mathrm{rGO}$ under different source of light.

\subsection{Electrical energy consumption}

Electrical energy consumption is also one of the important factors for selection of water treatment technology and its industrial applicability. Since photocatalytic degradation is an electric-intensive process for the removal of recalcitrant organic pollutant. Although, consumption of electrical energy is major representative of operating cost, quality goal and economics on large-scale. In this work, efficiency of treatment process based on electrical energy consumption was quantified using the concept of figure-of-merit electrical energy per order (Eq.-6). For visible treatment, the calculated EEO for GO mediated photodegradation was in the range of 20.09-29.95 ( $\mathrm{kW} \mathrm{h} \mathrm{L}^{-1}$ order $\left.^{-1}\right)$, which shows more consumption than $\mathrm{BaFe}_{2} \mathrm{O}_{4} / \mathrm{rGO}$ mediated visible treatment (16.08 to $22.79 \mathrm{kWhL}^{-1}$ order

${ }^{1}$ ). Above results show that $\mathrm{BaFe}_{2} \mathrm{O}_{4} / \mathrm{rGO}$ is more energy efficient than $\mathrm{GO}$, reason could be more reactive site and generation of radical for photodegradation of such low concentration organic pollutant. For solar driven system, energy efficiency was quantified during UV treatment. Evidently, EEO of $\mathrm{GO}$ and $\mathrm{BaFe}_{2} \mathrm{O}_{4} / \mathrm{rGO}$ was ranging from 0.59 to $1.71 \mathrm{~kW} \mathrm{~h} \mathrm{~L}^{-1}$ order $^{-1}$ and 0.76 to $1.14 \mathrm{~kW} \mathrm{~h}$ $\mathrm{L}^{-1}$ order $^{-1}$, respectively. This higher EEO values of visible treatment could enhance the efficiency of solar treatment (45\% visible and 4\% UV) (Santiago-Morales et al., 2013). Additionally, reusability of $\mathrm{GO}$ and $\mathrm{BaFe}_{2} \mathrm{O}_{4} / \mathrm{rGO}$ was also investigated, and results were showed good stability even after 3 cycle of $\mathrm{BaFe}_{2} \mathrm{O}_{4} / \mathrm{rGO}$ (Fig.5d).

\section{Conclusion}

In this study, synthesized $\mathrm{BaFe}_{2} \mathrm{O}_{4} / \mathrm{rGO}$ showed enhanced catalytic activity for degradation of CHD in comparison to GO. The structural properties were affected by doping of $\mathrm{Ba}^{2+}$ showed decreased band energy of catalyst, which enhanced the photocatalytic degradation of CHD. Characterization results (EDS, XPS and XRD) confirm the crystallinity of the structure and doping on the surface of sample that may favour the photocatalytic degradation of CHD by separation of charge carrier. The result of kinetic studies showed that pseudo first order kinetic model was well fitted, based on the rate constant and $\mathrm{R}^{2}$ values. The trapping experiment tests demonstrated that the major reactive oxygen species are ${ }^{\circ} \mathrm{OH}$ radicals and photogenerated electrons for $\mathrm{CHD}$ degradation. Based on intermediate analysis as well as reduction in TOC and $\mathrm{UV}_{254}$, it was observed that $\mathrm{GO}$ and $\mathrm{BaFe}_{2} \mathrm{O}_{4} / \mathrm{rGO}$ decompose complex long chain into shorter chain species, thus their bacterial toxicity was also reduced during photocatalysis process. The efficiency of as prepared catalyst was examined in the use of energy and the results are higher than previous studies due to the removal of refractory pollutant in the lower 
concentration. But comparative studies demonstrated that $\mathrm{BaFe}_{2} \mathrm{O}_{4} / \mathrm{rGO}$ would be the potential catalyst for solar-driven photocatalysis and maintain the sustainability. Overall results suggested that application of modified $\mathrm{BaFe}_{2} \mathrm{O}_{4} / \mathrm{rGO}$ photocatalyst for removal and efficient degradation of antibiotic pollutants could be achieved through adsorption and photocatalysis approach. Thus, the practical applicability of this catalyst could be exploited for significant removal of hydrophobic organic pollutant form others industrial wastewater.

\section{Acknowledgement:}

The authors are very thankful for the financial support from Indian Institute of Technology (Indian School of Mines), Dhanbad under a Junior Research Fellowship scheme funded by Ministry of Human Resource Development (MHRD), Government of India, New Delhi to carry out this research work. We would also like to acknowledge Aneek Kulia and Soni Kumari for their valuable time in data interpretation and formatting of the manuscript and Nanotechnology Research Centre (NRC), SRMIST for providing the instrumentation facilities.

\section{Ethics approval and consent to participate.}

Not applicable

\section{Consent for publication}

Not applicable

\section{CRediT authorship contribution statement}

Ms. Astha Singh: All experiment, analysis and interpretation of results, Conceptualization, Methodology, Investigation, Formal analysis \& Writing-Original Draft. (First Author)

Prof. Brijesh Kumar Mishra: Supervision, Conceptualization, Review \&Editing. (Corresponding Author)

\section{Funding}

$$
\text { Funding information is not applicable. }
$$

\section{Competing interests}

The authors declare that they have no competing interests.

\section{Availability of data and materials}


All data generated or analysed during this study are included in this published article [and its supplementary information files].

\section{$\underline{\text { Declaration of competing interest }}$}

The authors declare that they have no known competing financial interests or personal relationships that could have appeared to influence the work reported in this paper.

\section{References}

Aboubaraka, A.E., Aboelfetoh, E.F., Ebeid, E.Z.M., 2017. Coagulation effectiveness of graphene oxide for the removal of turbidity from raw surface water. Chemosphere 181, 738-746. https://doi.org/10.1016/j.chemosphere.2017.04.137

Azarpira, H., Sadani, M., Abtahi, M., Vaezi, N., Rezaei, S., Atafar, Z., Mohseni, S.M., Sarkhosh, M., Ghaderpoori, M., Keramati, H., Hosseini Pouya, R., Akbari, A., fanai, V., 2019. Photo-catalytic degradation of triclosan with UV/iodide/ZnO process: Performance, kinetic, degradation pathway, energy consumption and toxicology. J. Photochem. Photobiol. A Chem. 371, 423-432. https://doi.org/10.1016/j.jphotochem.2018.10.041

Bai, X., Du, Y., Hu, X., He, Y., He, C., Liu, E., Fan, J., 2018. Synergy removal of Cr (VI) and organic pollutants over RP-MoS2/rGO photocatalyst. Appl. Catal. B Environ. 239, 204-213. https://doi.org/10.1016/j.apcatb.2018.08.016

Casbeer, E., Sharma, V.K., Li, X.Z., 2012. Synthesis and photocatalytic activity of ferrites under visible light: A review. Sep. Purif. Technol. 87, 1-14. https://doi.org/10.1016/j.seppur.2011.11.034

Chen, Y., Zhang, X., Wang, L., Cheng, X., Shang, Q., 2020. Rapid removal of phenol/antibiotics in water by Fe-(8-hydroxyquinoline-7-carboxylic)/TiO2 flower composite: Adsorption combined with photocatalysis. Chem. Eng. J. 402. https://doi.org/10.1016/j.cej.2020.126260

Das, R., Sarkar, S., Bhattacharjee, C., 2014. Photocatalytic degradation of chlorhexidine-A chemical assessment and prediction of optimal condition by response surface methodology. J. Water Process Eng. 2, 79-86. https://doi.org/10.1016/j.jwpe.2014.05.005

El-Sheikh, S.M., Khedr, T.M., Hakki, A., Ismail, A.A., Badawy, W.A., Bahnemann, D.W., 2017. Visible light activated carbon and nitrogen co-doped mesoporous TiO2as efficient photocatalyst for degradation of ibuprofen. Sep. Purif. Technol. 173, 258-268. https://doi.org/10.1016/j.seppur.2016.09.034

Fidelis, M.Z., Abreu, E., Dos Santos, O.A.A., Chaves, E.S., Brackmann, R., Dias, D.T., Lenzi, G.G., 
2019. Experimental design and optimization of triclosan and 2.8-diclorodibenzeno-p-dioxina degradation by the Fe/Nb 2 O 5 /UV system. Catalysts 9, 1-18. https://doi.org/10.3390/catal9040343

Han, J.K., Song, D.S., Lim, Y.R., Song, W., Myung, S., Lee, S.S., An, K.S., Jung, H.K., Santucci, S., Esposito, V., Lim, J., 2021. In-depth exploration of the synergistic interplay between perovskite barium titanate nanoparticles and two-dimensional graphene oxide for flexible piezoelectric nanogenerators. Appl. Surf. Sci. 538, 147962. https://doi.org/10.1016/j.apsusc.2020.147962

Hu, Z., Ge, M., Guo, C., 2020. Efficient removal of levofloxacin from different water matrices via simultaneous adsorption and photocatalysis using a magnetic Ag3PO4/rGO/CoFe2O4 catalyst. Chemosphere 128834. https://doi.org/10.1016/j.chemosphere.2020.128834

Li, M. fang, Liu, Y. guo, Zeng, G. ming, Liu, N., Liu, S. bo, 2019. Graphene and graphene-based nanocomposites used for antibiotics removal in water treatment: A review. Chemosphere 226, 360-380. https://doi.org/10.1016/j.chemosphere.2019.03.117

Nasseh, N., Taghavi, L., Barikbin, B., Nasseri, M.A., 2018. Synthesis and characterizations of a novel FeNi3/SiO2/CuS magnetic nanocomposite for photocatalytic degradation of tetracycline in simulated wastewater. J. Clean. Prod. 179, 42-54. https://doi.org/10.1016/j.jclepro.2018.01.052

Nidhi, K., Indrajeet, S., Khushboo, M., Gauri, K., Sen, D.J., 2011. Hydrotropy: A promising tool for solubility enhancement: A review. Int. J. Drug Dev. Res. 3, 26-33. https://doi.org/10.1002/jps

Priya, T., Prakash, P., Mishra, B.K., 2018. Understanding the coagulant activity of zirconium oxychloride to control THMs formation using response surface methodology. Ecotoxicol. Environ. Saf. 159, 28-37. https://doi.org/10.1016/j.ecoenv.2018.04.036

Roonasi, P., Mazinani, M., 2017a. Synthesis and application of barium ferrite/activated carbon composite as an effective solar photocatalyst for discoloration of organic dye contaminants in wastewater. J. Environ. Chem. Eng. 5, 3822-3827. https://doi.org/10.1016/j.jece.2017.07.035

Roonasi, P., Mazinani, M., 2017b. Synthesis and application of barium ferrite/activated carbon composite as an effective solar photocatalyst for discoloration of organic dye contaminants in wastewater. J. Environ. Chem. Eng. 5, 3822-3827. https://doi.org/10.1016/j.jece.2017.07.035

Santiago-Morales, J., Gómez, M.J., Herrera-López, S., Fernández-Alba, A.R., García-Calvo, E., Rosal, R., 2013. Energy efficiency for the removal of non-polar pollutants during ultraviolet irradiation, visible light photocatalysis and ozonation of a wastewater effluent. Water Res. 47, 5546-5556. https://doi.org/10.1016/j.watres.2013.06.030

Schneider, J., Matsuoka, M., Takeuchi, M., Zhang, J., Horiuchi, Y., Anpo, M., Bahnemann, D.W., 2014. Understanding $\mathrm{TiO}_{2}$ Photocatalysis: Mechanisms and Materials. Chem. Rev. 114, 99199986. https://doi.org/10.1021/cr5001892

Singh, M., Kaushal, S., Singh, P., Sharma, J., 2018. Boron doped graphene oxide with enhanced photocatalytic activity for organic pollutants. J. Photochem. Photobiol. A Chem. 364, 130-139. 
https://doi.org/10.1016/j.jphotochem.2018.06.002

Sonal, S., Prakash, P., Mishra, B.K., Nayak, G.C., 2020. Synthesis, characterization and sorption studies of a zirconium(IV) impregnated highly functionalized mesoporous actIVated carbonsb. RSC Adv. 10, 13783-13798. https://doi.org/10.1039/c9ra10103a

Sonal, S., Singh, A., Mishra, B.K., 2018. Decolorization of reactive dye Remazol Brilliant Blue R by zirconium oxychloride as a novel coagulant: Optimization through response surface methodology. Water Sci. Technol. 78, 379-389. https://doi.org/10.2166/wst.2018.307

Sousa, C.P., de Oliveira, R.C., Freire, T.M., Fechine, P.B.A., Salvador, M.A., Homem-de-Mello, P., Morais, S., de Lima-Neto, P., Correia, A.N., 2017. Chlorhexidine digluconate on chitosanmagnetic iron oxide nanoparticles modified electrode: Electroanalysis and mechanistic insights by computational simulations. Sensors Actuators, B Chem. 240, 417-425. https://doi.org/10.1016/j.snb.2016.08.181

Thakur, K., Kandasubramanian, B., 2019. Graphene and Graphene Oxide-Based Composites for Removal of Organic Pollutants: A Review. J. Chem. Eng. Data 64, 833-867. https://doi.org/10.1021/acs.jced.8b01057

Wang, H., Zhang, M., He, X., Du, T., Wang, Y., Li, Y., Hao, T., 2019. Facile prepared ball-like TiO2 at GO composites for oxytetracycline removal under solar and visible lights. Water Res. 160, 197-205. https://doi.org/10.1016/j.watres.2019.05.073

Wang, X., Xu, G., Tu, Y., Wu, D., Li, A., Xie, X., 2021. BiOBr/PBCD-B-D dual-function catalyst with oxygen vacancies for Acid Orange 7 removal: Evaluation of adsorption-photocatalysis performance and synergy mechanism. Chem. Eng. J. 411, 128456. https://doi.org/10.1016/j.cej.2021.128456

Wang, Z.L., Xu, D., Huang, Y., Wu, Z., Wang, L.M., Zhang, X.B., 2012. Facile, mild and fast thermal-decomposition reduction of graphene oxide in air and its application in highperformance lithium batteries. Chem. Commun. 48, 976-978. https://doi.org/10.1039/c2cc16239c

Yuan, Q., Zhang, D., Yu, P., Sun, R., Javed, H., Wu, G., Alvarez, P.J.J., 2020. Selective Adsorption and Photocatalytic Degradation of Extracellular Antibiotic Resistance Genes by MolecularlyImprinted Graphitic Carbon Nitride. Environ. Sci. Technol. 54, 4621-4630. https://doi.org/10.1021/acs.est.9b06926

Zhang, X., Shen, J., Zhuo, N., Tian, Z., Xu, P., Yang, Z., Yang, W., 2016. Interactions between Antibiotics and Graphene-Based Materials in Water: A Comparative Experimental and Theoretical Investigation. ACS Appl. Mater. Interfaces 8, 24273-24280. https://doi.org/10.1021/acsami.6b09377

Zhu, C., Chen, X., Ma, J., Gu, C., Xian, Q., Gong, T., Sun, C., 2018. Carbon Nitride-Modified Defective TiO2- x@Carbon Spheres for Photocatalytic H2 Evolution and Pollutants Removal: 
644 https://doi.org/10.1021/acs.jpcc.8b06624

645 Zwiener, C., Frimmel, F.H., 2000. Oxidative treatment of pharmaceuticals in water. Water Res. 34, 646 1881-1885. https://doi.org/10.1016/S0043-1354(99)00338-3

647 
Figures

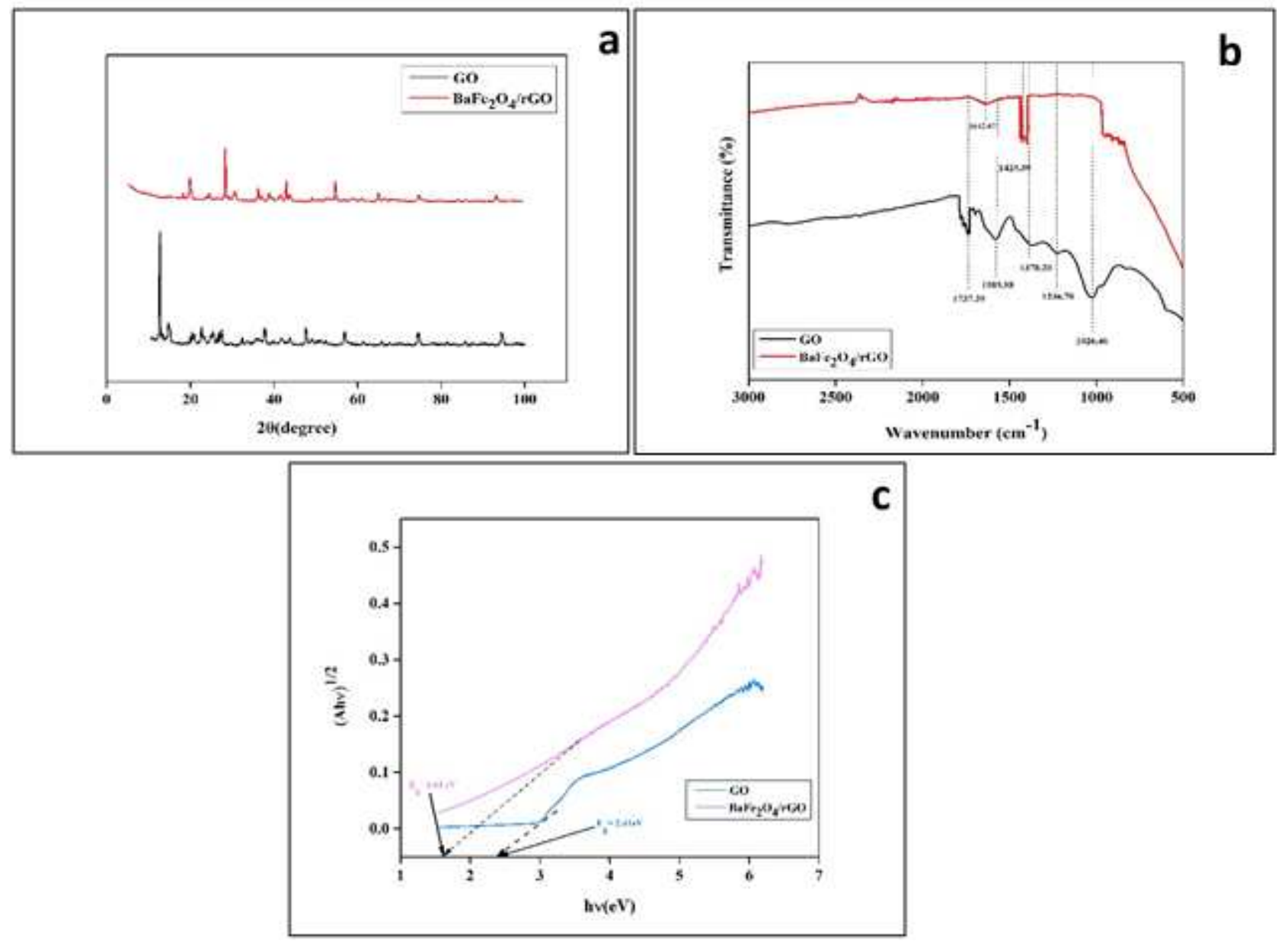

Figure 1

a) XRD patterns; b) FTIR spectra and c) UV-vis diffuse reflectance spectra of GO and BaFe204/rGO. 

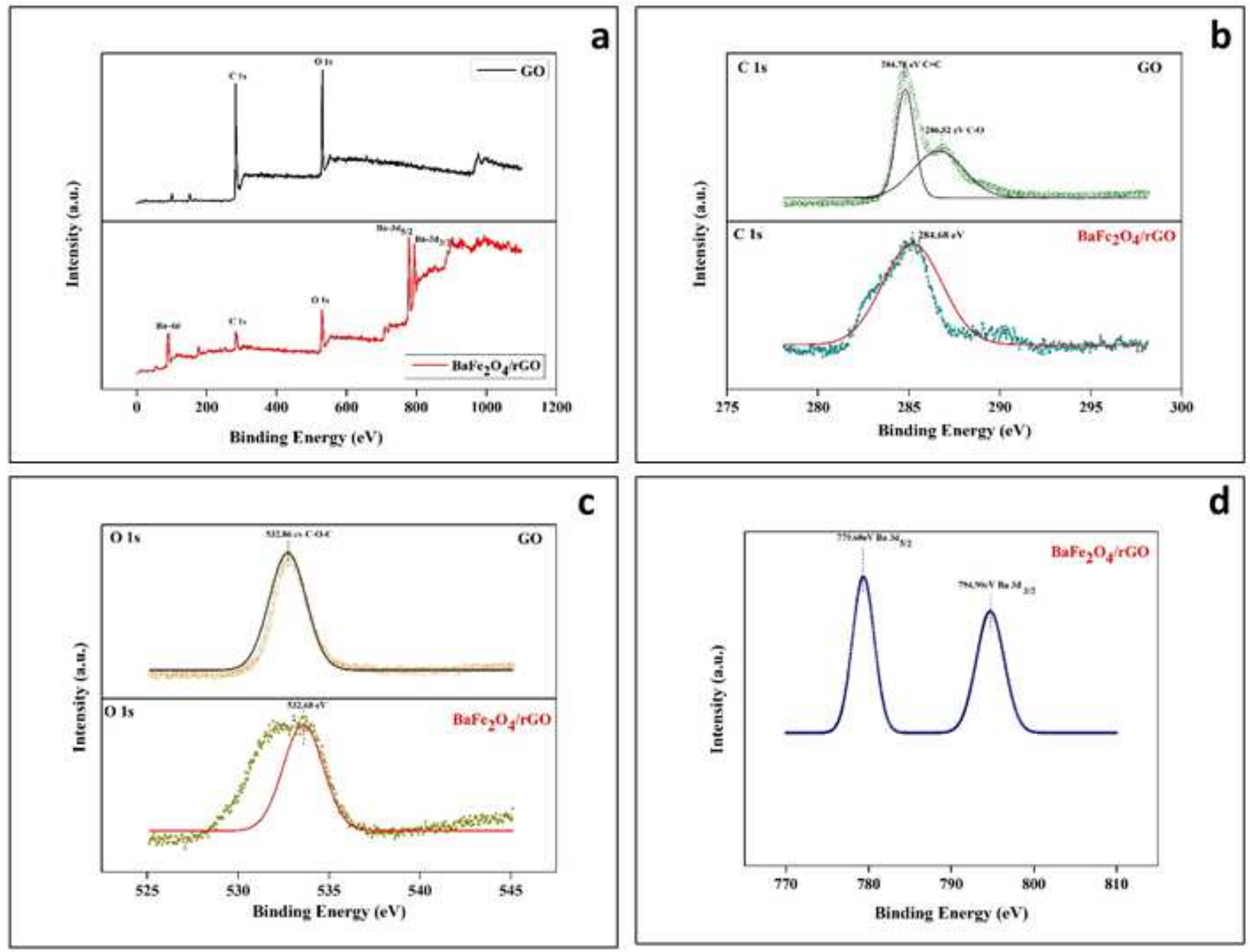

Figure 2

a) Full scan spectra and extended high-resolution b) C 1s; c) 0 1s and d) Ba 3d spectra of GO and BaFe2O4/rGO. 

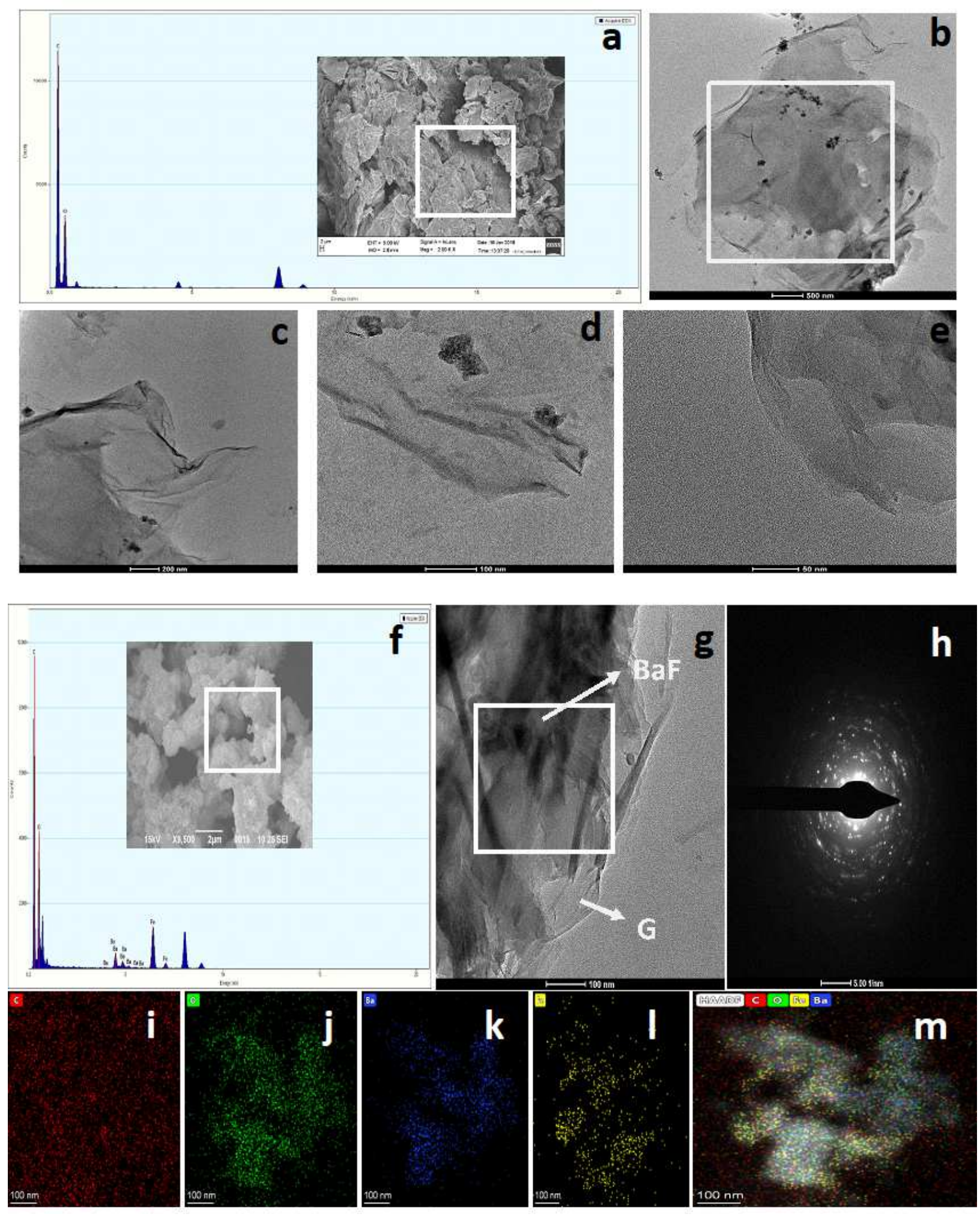

Figure 3

SEM, TEM and EDS images of photocatalysts (a-e) GO; and (f-m) BaFe204/rGO. 

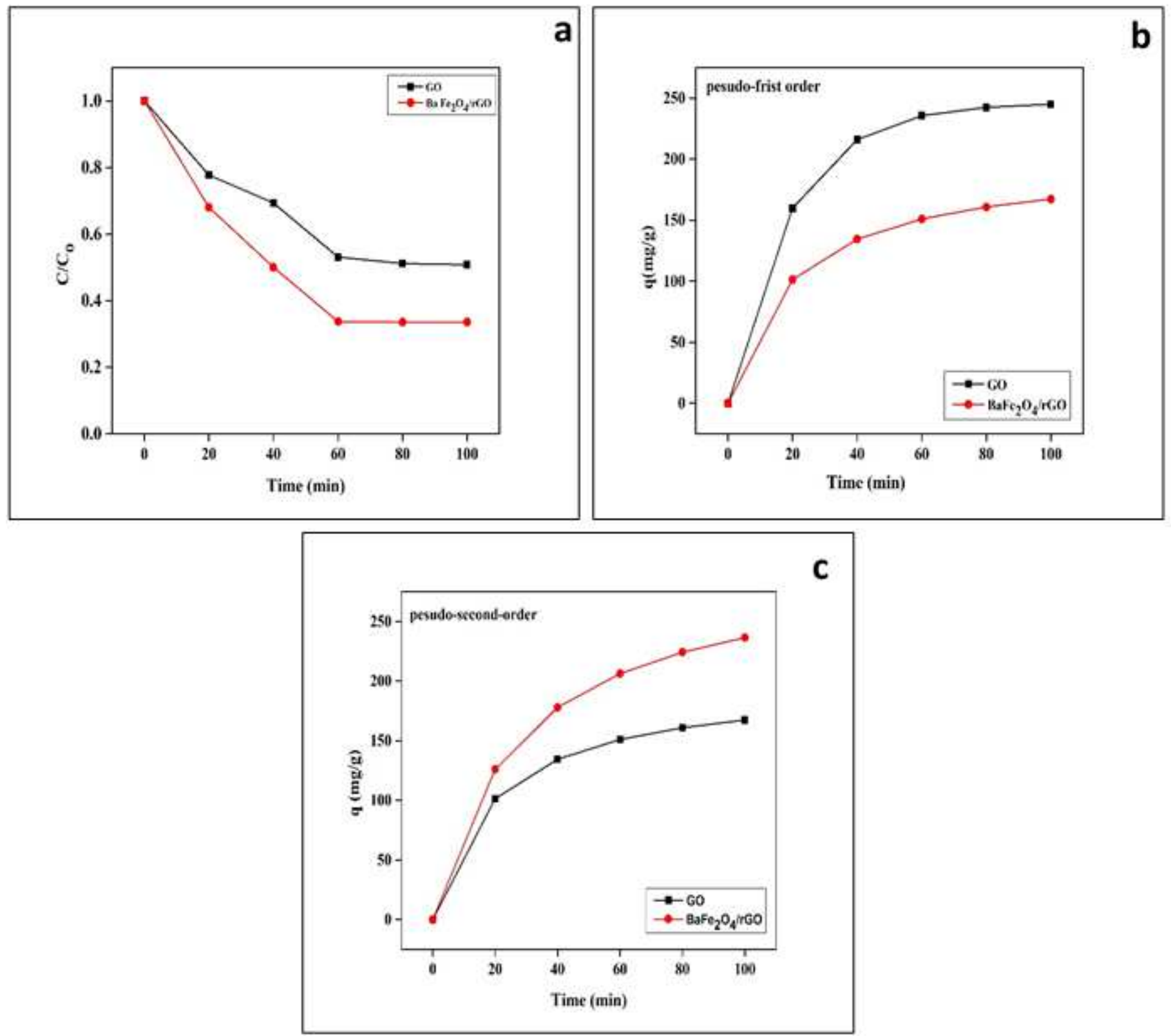

Figure 4

a) Adsorption of $\mathrm{CHD}$ at optimized condition; b) pseudo-first order model; and c) pseudo-second order model for GO and BaFe2O4/rGO. 


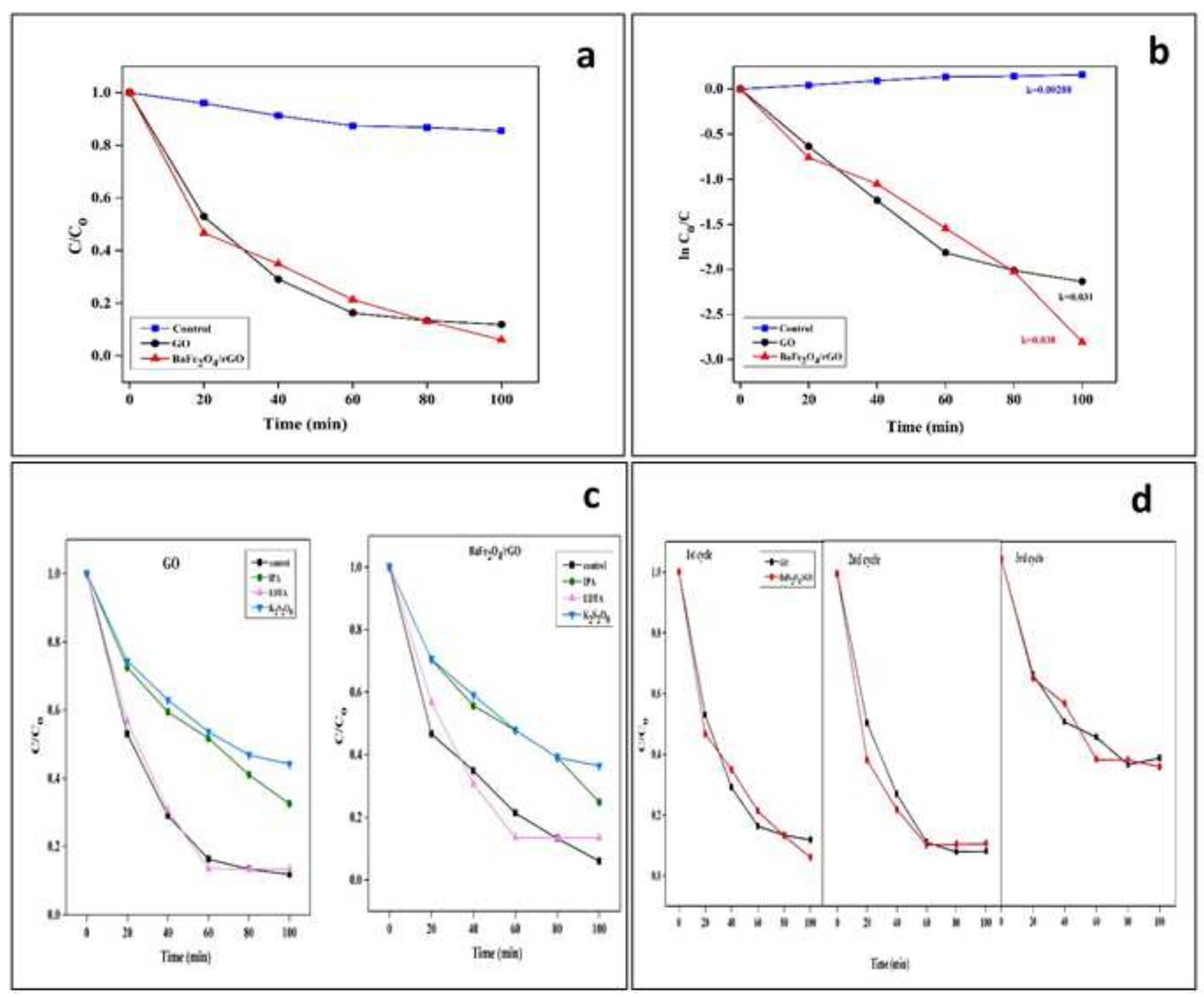

Figure 5

a) Photocatalytic degradation of $\mathrm{CHD}$ at optimized condition; b) pseudo-first order kinetics; c) trapping experiment of active species; and d) reusability experiment of $\mathrm{GO}$ and $\mathrm{BaFe} 2 \mathrm{O} 4 / \mathrm{rGO}$ mediated photocatalytic degradation of CHD. 

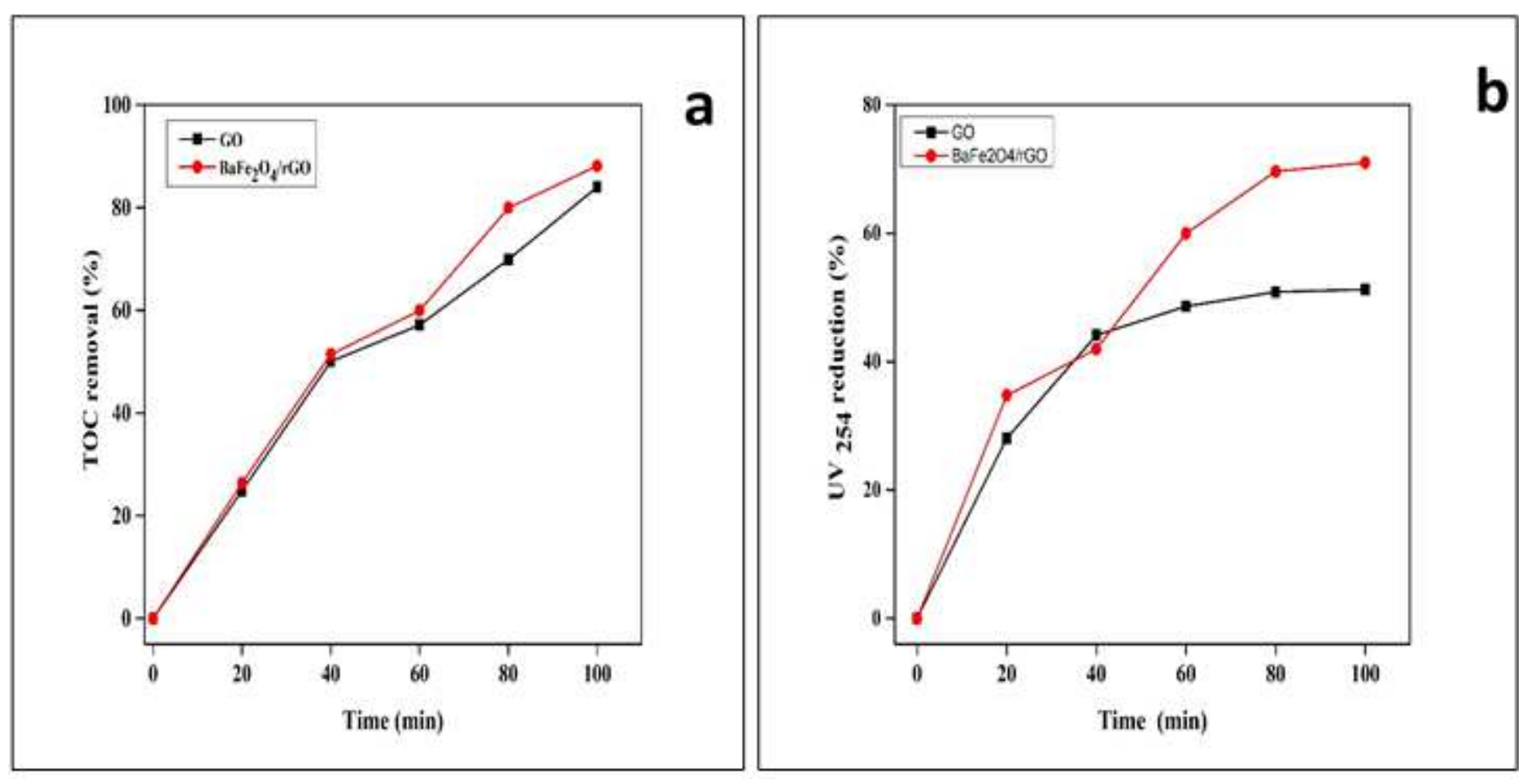

Figure 6

a) TOC removal and; b) UV absorbance reduction in $\mathrm{GO}$ and $\mathrm{BaFe} 2 \mathrm{O} 4 / \mathrm{rGO}$ mediated photocatalytic degradation of $\mathrm{CHD}$ at optimized condition.

\section{Supplementary Files}

This is a list of supplementary files associated with this preprint. Click to download.

- GA.png

- Supplementary.docx 